\title{
ArcheoSciences
}

Revue d'archéométrie

33 (suppl.) | 2009

Mémoire du sol, espace des hommes

\section{From Celtiberians to Romans: Combined geophysical (3D GPR and fluxgate gradiometer) prospection for the archaeological characterization of Castro de la Magdalena (León, Spain)}

Alexandre Novo, Roger Sala, Ekhine García, Robert Tamba, Fernando Muñoz, Mercedes Solla and Henrique Lorenzo

\section{(2) OpenEdition}

\section{Journals}

Electronic version

URL: https://journals.openedition.org/archeosciences/1409

DOI: 10.4000/archeosciences. 1409

ISBN: 978-2-7535-1599-4

ISSN: 2104-3728

\section{Publisher}

Presses universitaires de Rennes

\section{Printed version}

Date of publication: 30 October 2009

Number of pages: $121-124$

ISBN: 978-2-7535-0943-6

ISSN: 1960-1360

\section{Electronic reference}

Alexandre Novo, Roger Sala, Ekhine García, Robert Tamba, Fernando Muñoz, Mercedes Solla and Henrique Lorenzo, "From Celtiberians to Romans: Combined geophysical (3D GPR and fluxgate gradiometer) prospection for the archaeological characterization of Castro de la Magdalena (León, Spain)", ArcheoSciences [Online], 33 (suppl.) | 2009, Online since 30 October 2011, connection on 01 February 2022. URL: http://journals.openedition.org/archeosciences/1409 ; DOI: https://doi.org/ 10.4000/archeosciences.1409 


\title{
From Celtiberians to Romans: Combined geophysical (3D GPR and fluxgate gradiometer) prospection for the archaeological characterization of Castro de la Magdalena (León, Spain)
}

\author{
Alexandre Novo*, Roger Sala ${ }^{* *}$, Ekhine Garcia ${ }^{* *}$, Robert TambA**, \\ Fernando Muñoz ${ }^{* * *}$, Mercedes Solla* and Henrique Lorenzo*
}

Key words: 3D GPR, Fluxgate gradiometer, Roman archaeology, Celtiberian archaeology, Hill Fort.

\section{INTRODUCTION}

A 3D GPR investigation, combined with fluxgate magnetometer, has been carried out on a hill fort called Castro de la Magdalena in León (Northwest of Spain). The archaeological investigation started after remains of Celtiberian culture (dated from the first Iron Age) and a later Roman occupation were discovered in a town nearby.

Examples of archaeological prospection by means of multi-technique geophysical data over Roman remains are extended in the specialized literature (Sambuelli $e t$ al., 1999); (Sala \& Lafuente, 2007); (Peña et al., 2008). However, due to the lack of previous geophysical works over remains from Celtiberian cultures, their detection and characterization became more challenging. Besides, ground conditions of this particular site were characterized by the existence of a dense clay layer covered by multiple ploughing furrows which, although limiting the full poten- tial of GPR, do not avoid obtaining valuable information (Weaver 2006).

Main objective was to help archaeologists during the excavation planning and characterize the site. Another goal consisted on comparing the results of applying different 3D GPR data acquisition strategies and data processing schemes.

\section{Methodology}

The multi-technique geophysical prospection spread over two survey areas: The hill, where the fort is located, extends over $5140 \mathrm{~m}^{2}$ and the area situated south to the hill, which approximated extension is $10800 \mathrm{~m}^{2}$, where shallow excavations revealed clues of an undefined Roman settlement.

The hill was surveyed using two different GPR systems: A GSSI SIR-3000 system equipped with a $270 \mathrm{MHz}$ was

* EUET Forestal. University of Vigo, Campus A Xunqueira s/n.36005-Pontevedra (Spain). (alexnovo@uvigo.es), (hlorenzo@uvigo.es)

** SOT Archaeological Prospection, Avinguda de l'estació 37, baixos.08198-Sant Cugat del Vallès (Catalonia-Spain). (roger_sala_bar@yahoo.es), (ekhinegarcia@yahoo.com)

*** Talactor, S.L., C./ Ollería, 23, $1^{\circ}$ dcha.24008 León (Spain). (fernando@talactor.com) 


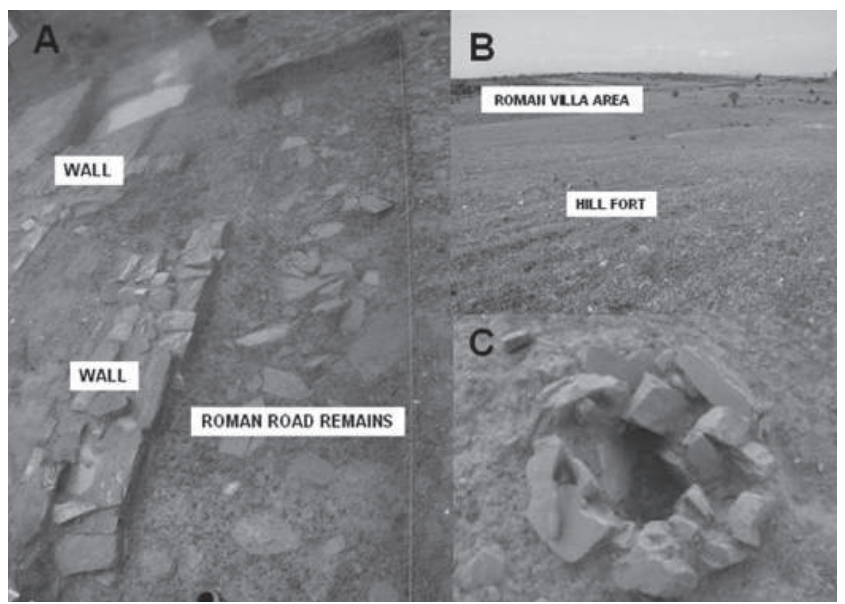

Figure 1: A shows the results of shallow excavations $(15-30 \mathrm{~cm})$ over the Roman settlement. B shows location of Roman villa and castro areas. C shows a silo from Celtiberian culture.

used for pseudo 3D data acquisition of the whole area, with a density of $0.40 \mathrm{~m}$ by $0.025 \mathrm{~m}, 512$ samples per scan and time window of $60 \mathrm{~ns}$. On the other hand, and following 3D ultra-dense grid strategies (Novo et al., 2008a), a RAMAC system with 250 and $500 \mathrm{MHz}$ antennas was only employed for surveying three small grids within the hill and with the goal of obtaining full-resolution 3D imaging of subtle archaeological targets (Novo et al., 2008b). Since the archaeological site was related with metal transformation and work, the GPR survey was complemented with a mag- netic survey using a Bartington 601 fluxgate gradiometer system to locate possible kilns, pits or metal remains.

Due to its large extension, much faster magnetic surveying suggested the application of this technique for completing the area situated south to the hill. However, as the other techniques could help to extract additional information, a pseudo 3D GPR survey with the SIR-3000 were effectuated over a grid of $400 \mathrm{~m}^{2}$ each.

\section{RESUltS}

\section{GPR}

The electrically lossy ground material attenuated much of the radar energy further than 30 ns. In addition, GPR data were influenced by poor ground-coupling as the antennas passed over many furrows linked with ploughing operations. So such local conditions could be the reason for the high scattering attenuation of the GPR data acquired. As a result, careful data processing was performed within GPR-SLICE v6.0 (Goodman, 2008) in order to extract some information and finally GPR slices showed a large group of anomalies which are related with human activity (Fig. 2 and 3).

After dewowing and gaining the data, pseudo $3 \mathrm{D}$ processing of data collected with the SIR-3000 system consisted on the generation of several sets of time-slices with different time windows to achieve the best view of archaeological features. The final interpretation was made over a set of

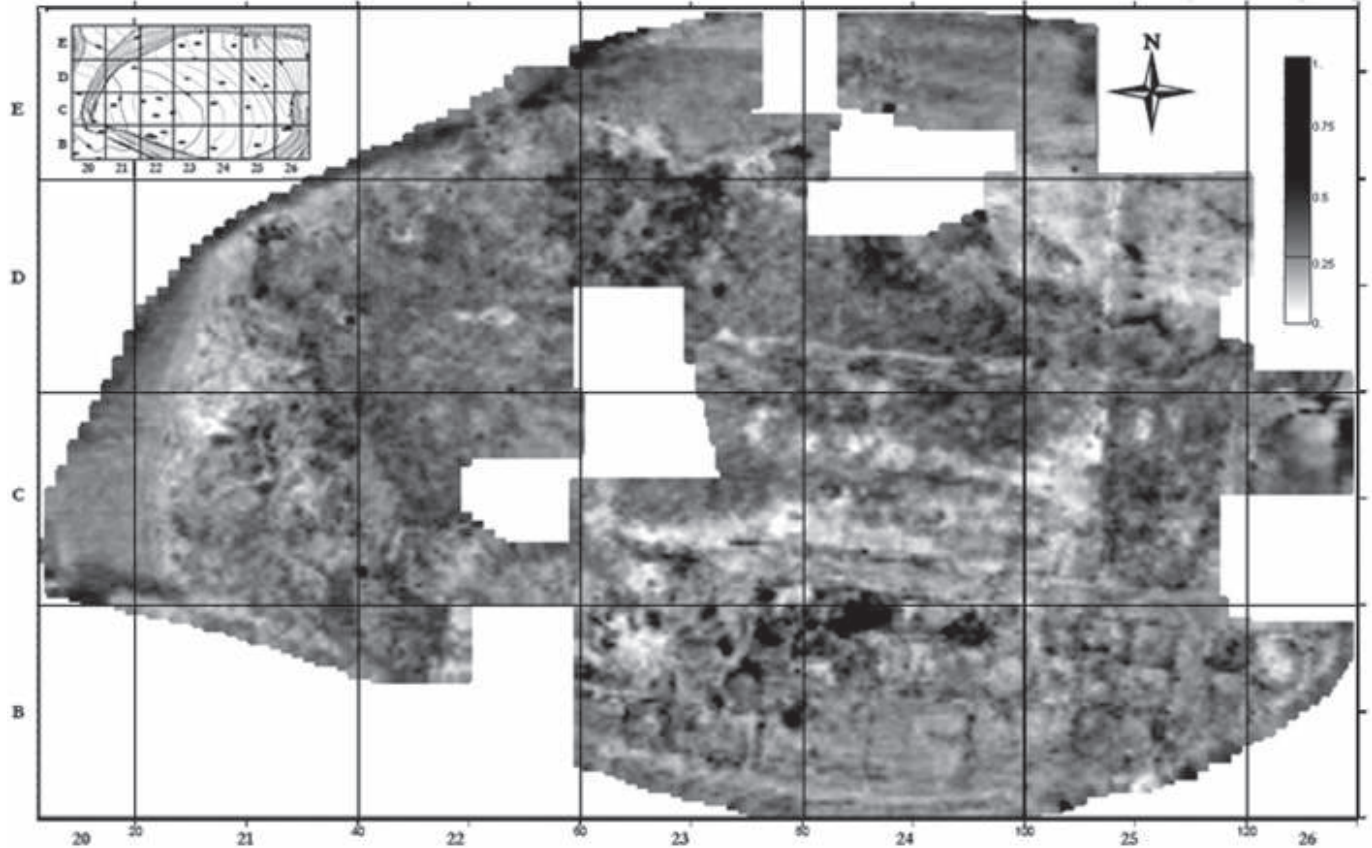

Figure 2: Slice 5 at $25-40$ $\mathrm{cm}$ shows many features of interest. 
Figure 3: Interpretative map of archaeological structures detected with GPR at $25-40 \mathrm{~cm}$. The hill fort area was divided into five sectors: North, South, East, West and Centre.

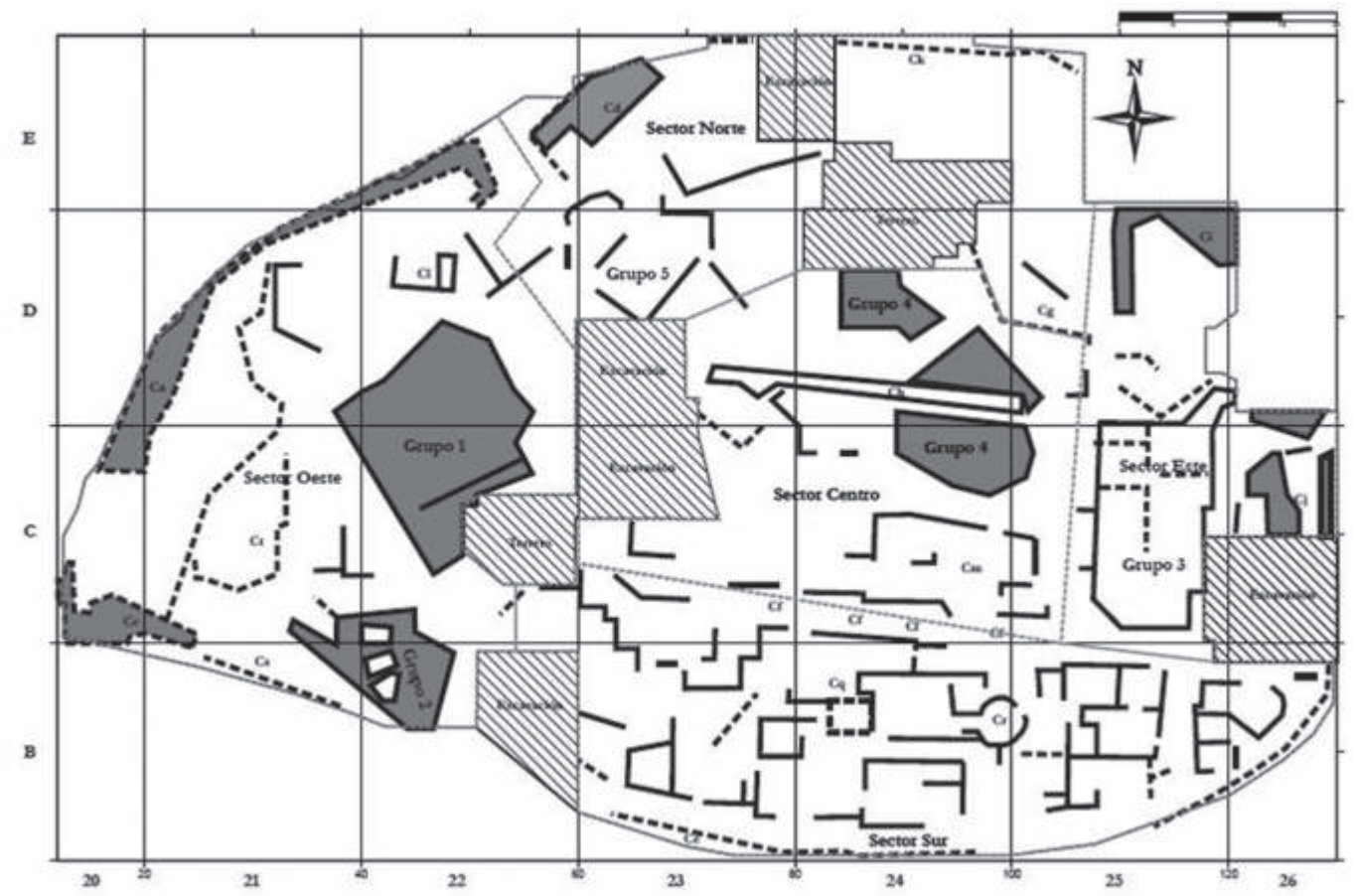

25 time-slices 3.75 ns thick by first calculating the squared amplitude of each trace and then gridding using the inverse distance algorithm and a search radius of 0.6 for interpolating areas without data. Time to depth conversion was performed with a velocity determined from hyperbola analysis and also in-situ velocity tests over building parts discovered in archaeological trenches.

On the other hand, data acquired by applying 3D ultradense grid strategies were extremely affected by soil and ground surface conditions. Fine 2D data processing involved the following filters: DC-shift subtracting, band pass within the time-domain, subtracting average, band pass frequency and gain compensation of the geometrical divergence losses. Then three-dimensional data volumes were generated and sliced into 1 sample thick horizontal depth-slices by using the absolute pulse values. Best visualization was obtained after applying a 9x9 low pass filter.

\section{Magnetic}

Magnetic data was collected in $0.5 \mathrm{~m}$ by $0.25 \mathrm{~m}$ resolution and the data processing consisted in line-mean correction and a $3 \times 3$ low pass filtering.

The results partially reproduce some of the walls detected with GPR, but as expected, the most valuable information was the position of high magnetic contrast anomalies interpreted as kilns and pits.
The survey area was extended to the south, where the archaeological team located roman pottery, iron slag and tegulae in the previous surface exploration. The magnetic survey revealed a full occupation of this southern side, with high contrast anomalies interpreted as kilns, pits and building remains. The diffuse shape of most features was interpreted as they are positioned at increasingly deeper levels due to erosion and slope, which was confirmed by radargrams collected in this area.

\section{ConClusions}

In spite of unfavourable soil conditions 3D GPR results show many constructive structures and distinguish levels with complex overlapping patterns. In this particular case, pseudo 3D GPR strategies were more effective because clayey soil properties and ploughing furrows strongly degraded full-resolution 3D imaging potential. On the other hand, magnetic surveys have helped to confirm some of the constructive structures and also detect anomalies with high magnetic contrast such as kilns, ferrous elements and clay floors.

These results demonstrate that combined 3D GPR and magnetic surveying are effective tools that can be used for mapping and characterizing castros, even in cases where remaining stratigraphy is very short. 


\section{Acknowledgments}

The authors want to thank $M^{a}$ Ángeles Sevillano Fuertes (Ayuntamiento de Astorga) and Jesús Celis Sánchez (Instituto Leonés de Cultura, Diputación de León) for supporting the investigation carried out in the site called Castro de la Magdalena (León, Spain).

\section{References}

Goodman, D., 2008. GPR-SLICE v6.0 Manual. From [http:// www.gpr-survey.com, November/2008].

Novo, A., Lorenzo, H., Rial, F. I., Pereira, M. and Solla, M., 2008a. Ultra-dense grid strategies for 3D GPR in Archaeology. 12th International Conference on Ground Penetrating Radar, 16-19 June, Birmingham, UK. CD-ROM.

Novo, A., Grasmueck, M., Viggiano, D. A. and Lorenzo, H., 2008b. 3D GPR in Archaeology: What can be gained from dense Data Acquisition and Processing?. 12th International Conference on Ground Penetrating Radar, 16-19 June, Birmingham, UK. CD-ROM.

Pena, J. A., Teixidó, T., Carmona, E. and Orfila, M., 2008. Geophysical prospectings in the Charterhouse's Roman kilns (Granada). An example of obtaining a priori information. Arqueología y territorio, 4: 217-232.

Sala, R., Lafuente, M., 2007. Visualising the Ibero-Roman site of Puig-Ciutat (Catalonia, Spain) from magnetic variations maps and GPR time-slices. Studijné zvesti. Archaeologického ústavu slovenskej akadémie vied, 41: 234-238.

Sambuelli, L., Socco, L.V. and Brecciaroli, L., 1999. Acquisition and processing of electric, magnetic and GPR data on a Roman site (Victimulae, Salussola, Biella). Journal of Applied Geophysics, 41: 189-204.

WEAVER, W., 2006. Ground-penetrating radar mapping in clay: success from South Carolina, USA. Archaeological Prospection, 13: $147-150$. 